\title{
TRAVESTISMO CULTURAL Y MESTIZAJE LATINOAMERICANO: APUNTES PARA UN ANÁLISIS ANTROPOLÓGICO
}

LATIN AMERICAN CULTURAL TRANSVESTISM AND MIX: NOTES FOR AN ANTHROPOLOGICAL ANALYSIS

\section{FERNANDO ALMAGUER RODRÍGUEZ1, NANCY RICARDO DOMÍNGUEZ²}

1 Universidad Católica de Santiago de Guayaquil. nalmaguerfernando2014@gmail.com

2 Universidad Católica de Santiago de Guayaquil. nancyevrdo@gmail.com

RESUMEN

La realidad existencial del hombre latinoamericano es el resultado de múltiples factores culturales e históricos convergentes. La diversidad expresiva de semejante ligazón híbrida ha generado una similar proporción de enfoques teóricos y metodológicos que, -desde distintas posturas de las ciencias sociales y humanas-, pretenden arrojar luz a un fenómeno tan singular como complejo. El mestizaje cultural posee la virtud de suprimir los excesos de exactitud con que cada componente étnico llegado su momento de esplendor, tenga edificado un sólido herramental sígnicosimbólico que conformaba distintivas formas cosmológicas. La interacción de cada una de estas cosmovisiones propició lo que se aborda en este ensayo como travestismo cultural. Su manifestación entitativa se halla tan delicadamente elaborada que develarla implica un recorrido imaginal que muestre los acercamientos y distancias ópticas de la mismidad y la alteridad.

PALABRAS CLAVE: hibridación, transculturación, travestismo, modernidad líquida, posmodernidad.

\section{ABSTRACT}

The existential reality of the Latin American man is the result of converging many cultural and historical factors. The expressive diversity of this hybrid mix has generated a similar proportion of theoretical and methodological approaches, -from different positions of the social sciences and humans- , intended to shed light on such a unique and complex phenomenon. The cultural mix has the virtue of removing the excesses of accuracy with which each ethnic component reached its heyday, and they had built solid signic-symbolic tools that formed different cosmological forms. The interaction of each of these world views led to what is discussed in this essay as a cultural transvestism. Its entitative manifestation is so delicately elaborated that an imaginary journey for reveal it, showing distances and ethnic approaches of sameness and otherness, is needed.

KEYWORDS: hybridization, transculturation, transvestism, liquid modernity, postmodernism. 


\section{INTRODUCCIÓN ALGUNAS CONSIDERACIONES FENOMENOLÓGICAS SOBRE LA IMAGEN MESTIZA Y SU TRAVESTUALIDAD}

Tenemos pues, en el continente todos los elementos de la nueva humanidad; gente mestiza, gente para quien la belleza es la razón mayor de toda cosa

(Vasconcelos, 1925).

Según Canclini (1990), el proceso de hibridación y mestizaje latinoamericano ha generado el producto cultural más complejo y auténtico de la modernidad en este hemisferio, en su vientre se nutren y eclosionan formas estéticas y de la vida social procedente de culturas muy diversas. Su escenario es tan versátil que ha sido capaz de preservar el rico folclor indígena junto a las tradiciones europeas y afroamericanas, ofreciendo valores identitarios de una dinámica y versatilidad única.

La dimensión transcultural de este proceso comprendió también el modo en que, tanto la conciencia como el aspecto exterior del hombre, se "viste" y se "desviste" en busca de su legitimidad entitativa, generándose un fenómeno que pudiera interpretarse como "Travestismo Cultural». Este se define como la apropiación de la imagen del otro, su asimilación y adaptación, como alternativa para construir una nueva entidad yoica, la que sólo es posible desde el lenitivo abandono de una parte del herramental sígnicosimbólico propio (es decir, todo el arsenal cultural de un pueblo o civilización, su reflejo en las distintas formas de orden social y su incidencia en la modelación del hombre, es decir, religión, formas morales, gastronomía, lengua, arte, arquitectura, costumbres, tradiciones, etc.), en función de alcanzar la estabilidad imaginaria generada por el mestizaje. En este sentido, se insiste en el concepto del psicoanálisis que plantea la imposibilidad de la totalidad ontológica de lo humano, sin la presencia de los opuestos.

Es imprescindible, para este análisis, definir algunas generalidades filosóficas que se hallan implicadas en la concepción fenomenológica del travestismo. Por ello revelar la implicación de la imagen como parte esencial de la travestualidad, se considera un imperativo para llegar a esclarecer cuestiones álgidas que permanecen estables en el perímetro del ser de lo travestual. Se acude entonces, a métodos propios de las ciencias sociales: análisis-síntesis, el históricológico y el análisis semiótico-hermenéutico, rescatándolos como imprescindibles para los propósitos de este ensayo.
Como es conocido, cada civilización desarroló un complejo herramental sígnico-simbólico de gran riqueza imaginal, que comprometió a cada grupo humano partícipe con un discurso legitimador de un patrimonio determinado. Esto dio lugar a formas identitarias poseedoras de códigos culturales de significación emblemática: una lengua común, religión, arte, sistemas morales, explotación de los recursos naturales, etc.

Aún así, el resultado de progresivas yuxtaposiciones históricas-culturales generó la urdimbre que tejió y decantó, indistintamente, un código simbólico propio de una u otra civilización. Mediante estudios históricos se puede observar la regularidad con las que las culturas de oriente y del occidente friccionan y se yuxtaponen, estableciendo, en cada encontronazo, nuevas formas de actividad social y por ende hacia nuevos cambios cosmovisiones filosóficas que generan sensibles cambios hacia el interior de cada civilización.

El ejemplo más significativo de esta simbiosis cultural entre el Oriente y Occidente lo es, sin dudas, la incorporación de las cosmovisiones judías al mundo europeo, dando lugar al herramental ideológico más completo y dinámico del cual se haya tenido noticia. La modelación ideológica de un sistema de pensamiento como el judeocristiano, que fusionó el saber judío junto al logos grecolatino, generó el herramental sígnico-simbólico más completo y complejo para ambos hemisferios, aportando a Occidente la materia prima ideológica fundamental para ejercer su progresiva expansión global.

Quedará Occidente obligado a "metabolizar" el ideal monoteísta hebreo, pero, inhabilitado para continuar usando el enorme precedente politeísta de su panteón. Aún así, el mundo occidental fue incapaz de prescindir del poder de la imagen religiosa; la cual servirá de vehículo para ajustar y centrar, bajo un mismo sistema ideológico a tantos pueblos que bajo el poder de la Roma imperial poseían las más disímiles formas de religiosidad. Todas ellas, dispuestas y reconocidas en formas simbólicas precisas. No les quedó, a estas, otro remedio que ajustarse a la nueva ideología cristiana donde progresivamente encontrarían, si bien no una participación hegemónica, sí la posibilidad de incorporar algunos elementos de culto al complejo imaginal judeo-cristiano.

Si se observan las primeras imágenes del cristianismo romano, o lo que se conoce como 
arte paleocristiano, se ve que no se ajustan a lo que se adora actualmente en las catedrales.

Por ejemplo, las primeras imágenes de Cristo jamás se representaron en la cruz, por el contrario, solía pintársele como un ser triunfante, un sabio, lleno de luz, parado o en posición de avanzar hacia el espectador, con aureola en su cabeza. Esto ha sido señalado por muchos historiadores como un Cristo-Helios, forma sincrética de Cristo con el dios Sol (Apolo), como algunos investigadores sugieren.

El ejemplo anterior pudiera servir de muestra primaria para señalar las distintas formas de lo que denominamos travestismo cultural, que suelen manifestarse en períodos en que se reajustan las identidades culturales al momento de su interacción, donde cada pueblo aporta uno o varios elementos simbólicos que se yuxtaponen y que luego darán lugar a nuevas formas imaginales de expresión cultural. Por otra parte, la imagen, -o el aspecto filosófico de ésta, como se tratará en este ensayo-, no es el simple reflejo de nuestros cuerpos en los espejos, en realidad lo que se trata es la cosmovisión socio-filosófica que tienen los seres humanos en épocas determinadas. Esta genera un producto cultural singular en cada período histórico, definiendo incluso el inicio y fin de formas estéticas de la vida como estilos arquitectónicos, modas, formas de explotación de los recursos naturales, e incluso hasta la propia concepción de lo humano y su actividad social.

Para la imagen, "el mundo concreto", solo será su medio de expresión, la imagen será entonces un producto ontológico propiciado a su vez por nuestra necesidad de aprehensión subjetiva de la realidad. El arte, por ejemplo no se convertirá en imagen hasta tanto se encuentre el modo de interpretarlo en torno a las necesidades de la época que lo produce, es decir, al develar su significado sucederá el acto de aprehensión imaginal.

Es por ello, que un objeto ordinario, una secuencia de procesos o fenómenos, pueden ser llevados hoy a una galería y convertirse en motivo de reflexión estética por parte del público perceptor. Por consiguiente, alcanzarán el status de imagen cuando se conviertan en objeto de introspección, creando enlaces polisémicos con la realidad, que rebelarán las sustancias axiológicas que caracterizan determinado momento histórico-social. Sobre esto se puede agregar que, el significado encarnado permite entender las diferencias entre el arte moderno y el posmoderno; lo que el artista aprovecha para propiciar el discurso artístico siendo además, lo que le otorga la condición de arte a objetos, procesos o fenómenos. Su grado atractivo o de belleza, estará supeditado al capital cultural del perceptor que puede hallar en ellos los más disímiles encuentros con su realidad particular.

El concepto de significado encarnado es tomado de Danto (2005). Según este autor, uno de los factores claves para entender las diferencias entre el arte moderno y el posmoderno se encuentran en los procesos de significación y resignificación de objeto, y donde el arte también cooperó como objeto de re-semantización creándose lo que se conoce como intertextualidad.

\section{UNA SINGULAR VISIÓN CRÍTICA DEL SER Y LA IMAGEN DE LO RELIGIOSO, DESDE LAS PROFECÍAS DE ISAÍAS}

Ninguna aventura, ningún deseo donde el hombre ha intentado vencer una resistencia, ha dejado de partir de una semejanza y de una imagen; él siempre se ha sentido como un cuerpo que se sabe imagen, pues el cuerpo al tomarse a sí mismo como cuerpo, verifica tomar posesión como imagen (Lezama, 2010).

Debe reconocerse la curiosidad filosófica que puede producirse al reflexionar sobre las $\mathrm{pa}^{-}$ labras del profeta Isaías. Su intuición crítica caracterizó tempranamente al hombre como un ser que se constituye en la imagen. Advertir sobre las catastróficas consecuencias de tal situación, pudiera considerarse como un gran aporte a la antropología filosófica, según refiere en La Santa Biblia (1569).

El carpintero tiende la regla, hace el trazo con un marcador, labra con la gubia, traza con el compás y le da forma de hombre y de belleza humana, para colocarlo en una casa. Corta cedros para sí; escoge una conífera o un roble y lo deja crecer entre los árboles del bosque. Planta un pino, y la lluvia lo hace crecer. Luego se sirve de ellos para hacer fuego. Toma uno y con él se calienta; prende fuego y cuece pan. Hace, además, un dios, y lo adora; hace un ídolo y se postra ante él. Quema parte del leño en el fuego y sobre él prepara carne asada, come y se sacia. Luego se calienta y dice: "iAh! Me caliento mientras contemplo el fuego". Después, lo que sobra lo transforma en la imagen tallada de un dios. Se postra ante él y lo adora, y le ruega diciendo: iLíbrame, porque tú eres mi dios! (Isaías 44: 13-17).

La cuestión de interés es la propia concepción de Isaías sobre la imagen como forma de representación del ego mediante la estructuración del otro. La imagen, como se ve, es aquella 
herramienta salida de la conciencia humana que el profeta advierte como un abismo moral decadente, ya que su condición de otredad solo está dispuesta a legitimar al hombre mismo, es decir, a satisfacer su ego. Por tanto, señala y condena la imagen, precisamente por su efecto antiaxiológico y erosivo para el alma humana. Sobre las consecuencias que acarrea un mundo sostenido por la imagen, como se vive en la actualidad.

La imagen de aquel dios construido por el carpintero jamás será "real» como el hombre mismo, pero éste necesita del "placer travestual de la apariencia" para completar su cosmovisión de la realidad. Como expresaría el mismo Hegel (1995) jamás percibimos lo real sino a través de lo aparente es el hombre un animal que necesita construirse así mismo, y se constituye elevando al plano ideal el mundo que le rodea, del cual sublima simbólicamente aquello que, a su vez, lo mantendrá en sujeción, haciendo de su consciencia una paradójica expresión de creación y sometimiento.

Las reflexiones del profeta hacen pensar al hombre como un singular ser limitado en su interacción con la naturaleza, -incluso con su propia naturaleza-, límites que no puede superar sin antes establecer un argumento mítico o psíquico, el cual se manifestará como imagenego. De ello se puede extraer una premisa filosófica, no existe proceso de humanización hasta tanto no surja la consciencia simbólica, es decir la imagen. Paradójicamente, la imagen creó el abismo que separa y conjuga en un mismo ser dos naturalezas, la simbólica y la biológica.

La imagen, por tanto, es causa y efecto del proceso de humanización y esto se convierte de hecho en una relación dialéctica que será definitoria para la evolución de la cultura. No se puede fingir la existencia de lo humano en un ser anterior al proceso de creación de la imagen, aunque se comparta el mismo material genético de nuestros antepasados (aquellos que marcaron las primeras incisiones en las paredes de las cavernas, los que verdaderamente iniciaron el proceso de humanización).

Esto sitúa nuestra condición existencial bajo características muy singulares, los humanos son los únicos seres que llevarían una vida fragmentada de todo el universo de la naturaleza. Una situación de pulsión que constantemente enfrenta dos realidades, la biológica y la antropológica. Esta misma razón existencial es la que los convierte en una entidad, al entender por existencia un ente que posee una relación con su propio ser y una comprensión de este ser, el hombre se convierte en una entidad, ya que cumple con estas funciones. Según la define Heidegger (1988), es posible gracias a aquella facultad de auto-construcción simbólica, en la cual, la imagen surge con especial autoridad por ser emanada de la conciencia colectiva, ganando así su privilegio ontológico. Al respecto Marcuse (1978) señaló:

El animal hombre llega a ser un ser humano sólo por medio de una fundamental transformación de su naturaleza que afecta no sólo las aspiraciones instintivas, sino también los valores instintivos -esto es, los principios que gobiernan la realización de estas aspiraciones (...) el individuo existe, como quien dice, en dos dimensiones diferentes, caracterizadas por procesos mentales y principios diferentes. (p.25)

Se pueden mencionar varios ejemplos sobre el papel que ha jugado la producción imaginal en la construcción del ser de lo humano; pero continuando con la ontología bíblica se observa que la construcción identitaria del pueblo hebreo no fue posible hasta tanto no surge la fricción entre éstos y los egipcios. La experiencia de sometimiento les brindó las herramientas necesarias para su emancipación. Como es lógico, un proceso emancipatorio de tal índole se manifiesta creando diferencias culturales radicales. El monoteísmo hebreo es, en gran medida, una manifestación resultado de esta identidad emancipada que ha sabido distanciarse del otro, pero que tomó aquel para designar su propio herramental sígnico-simbólico.

Como suele plantearse la identidad cultural es un proceso que suele alcanzar su legitimidad, al estar provisto de un herramental simbólico suficientemente sustancioso, capaz de direccionar cuan provechoso sería asimilar y/o rechazar la otredad. Incluso al analizar fenómenos de simbiosis cultural muy común en toda América, se observa que algo se pierde, algo se ha cedido de cada parte étnica que ha venido a conformar una nueva identidad mediante aquel proceso conocido como transculturación.

Precisamente allí, en el interactuar, en el roce físico de cada cultura es que surgen formas propias del ser de lo travestual. Alguna forma simbólica de las culturas participantes y destinadas a converger simbióticamente ha de parecerle extraña las manifestaciones simbólicas de otredad. Aún cuando se inicia la asimilación 
del herramental simbólico ajeno se está en presencia del fenómeno de la travestualidad cultural.

Al parecer a una de las dos culturas debe resultarle más completo y eficaz parte del complejo sígnico-simbólico del otro, -aunque en realidad los aportes serán mutuos-, como para asimilarlo y apropiarse de él, no sin antes configurar aquellas adaptaciones necesarias o adecuadas que, desde el entendimiento de su mismidad sería de vital importancia. Debido a este fenómeno una deidad perteneciente a una etnia determinada podría verse forzada a modificar su imagen asumiendo las vestes o los símbolos de poder de otra deidad ajena hasta entonces, y perteneciente al panteón de aquella nueva o "extraña" etnia o cultura. Este proceso, evidentemente, no suele suceder inmediatamente, debe transcurrir un período relativamente largo como para que ambas formas culturales interpreten y asuman estos herramentales sígnicos-simbólicos.

Suele tener vital importancia el aspecto estético de algunas manufacturas, muy perfeccionadas simbólicamente por una de las culturas partícipes, y anhelada por la otra. Como es conocido, entre las culturas caribeñas ejerció una gran influencia el aporte del componente africano en todas las esferas de su imaginario social. Hoy puede afirmarse que los elementos identitarios que comparte el Caribe, fueron acrisolados por la virtud lenitiva del africano desde su música, su gastronomía y, en gran medida, por sus singulares expresiones religiosas.

Entre sus prácticas religiosas ocasionó un fuerte impacto transcultural, el hecho de poder usar vistosas telas para la confección de los vestuarios de aquellos que se iniciaban en la Regla de Ocha o Santería -la cual exige vestir al iniciado del color apropiado perteneciente a su Orisha o deidad tutelar-, ya que cada deidad del panteón afrocaribeño posee un color que la define e identifica. La Santería o Regla de Osha, comprende todo el herramental sígnico-simbólico de la religión Yoruba, su panteón es muy extenso y dinámico, es una región politeísta que ha asimilado el santoral católico a partir de la identificación y yuxtaposición de santos y vírgenes con los Orishas o deidades africanas, posee un complejo sistema de adivinación basado en la numerología que sus sacerdotes (Santeros y Babalawos) dominan aún en lengua yoruba.

Como se ha visto, en el roce forzoso que se estableció durante el proceso de formación de las naciones latinoamericanas y caribeñas, -donde convergió una diversidad muy amplia de elementos folclóricos-, se estableció una especie de competencia y yuxtaposición de sus herramentales simbólicos como expresión de apropiación intercultural. Estas transferencias, hasta tanto no se consoliden en un cuerpo simbólico nuevo, podrán entenderse como típicas experiencias travestuales desde una u otra de las partes participantes.

La yuxtaposición intercultural genera verdaderamente una competencia travestual que suele transcurrir mientras suceden procesos como: (1) aculturación, (2) transculturación e (3) inculturación.

1. Generalmente el sujeto procedente de una cultura determinada asume los atributos del herramental sígnicosimbólico de otredad, realizándose este proceso por sometimiento o inducción hegemónica.

Durante el proceso de colonización en América, muchos indígenas debieron asumir el cristianismo bajo la presión ideológica de las metrópolis, pero su participación religiosa influyó en la asunción de determinados arquetipos del vestuario. Era imprescindible que el indio entrara a la iglesia vestido con cierta dignidad y mientras más cercana fueran sus ropas al arquetipo de la usanza europea eran mejor aceptados. Por ello, tanto el indígena, como el negro, practicaron el uso de atuendos (disfraces) nada significativos para ellos en un inicio, pero de vital importancia si es que querían ganar el favor de un tipo de sociedad en la que se gestaba un fuerte proceso de aculturación.

2. Con relación al uso del vestuario por razones morales, si bien en el primer caso los atributos del vestuario no tienen una significación más allá del hecho de ganar el favor del tipo de sociedad imperante, en este segundo instante el sujeto asume los elementos ideológicos hegemónicos y los va incorporando a su herramental sígnico-simbólico. Este proceso es parte de lo que llamamos transculturación.

La modificación de la conciencia del sujeto se intensifica y deja de resistirse a la participación del nuevo modelo estructural, interviene en la actividad socioreligiosa y aporta elementos simbólicos de su acervo cultural. Incorporando ele- 
mentos claves de su imaginario que enriquecerán la experiencia hierofánica, convirtiéndola en un suceso menos mimético y más polisémico. Este será el momento en que se pueda explicar otra expresión del travestismo cultural, la inculturación.

3. La mezcla o simbiosis surgida del fenómeno transcultural es aceptada entonces por el herramental simbólico hegemónico. Por ejemplo la iglesia acepta modificaciones como vírgenes o cristos mestizos, o la intromisión de elementos discursivos de referencia indígena en fachadas de catedrales y templos. Durante este proceso surgen las formas travestuales del encubrimiento del otro, como lo denomina (Dussel, 1994).

Sobre el fenómeno interculturaly sus implicaciones ético-estéticas Barthes señaló la condición travestual que asumía el sujeto que, habiendo dejado su herramental sígnico-simbólico se transformaba evadiendo las fronteras de lo conocido, para asumir otra cultura, su religión, su lengua y, en gran medida esto se hacía más palpable al asumir otro vestuario. "Los travestis son cazadores de la verdad, lo que les da más horror es precisamente parecer disfrazados" (Barthes, 1978, p. 209). El sujeto que está siendo sometido a un proceso de aculturación participa de cambios psicosociales tan profundos que comienza a generar un intenso extrañamiento ético-estético de su identidad. En muchos casos, los propios atuendos que conformaban estereotipos étnicos serán devaluados lentamente hasta adquirir la dimensión del disfraz. Ajustarse al modo de vida occidental y europeizante para el indio americano, significó un distanciamiento simbólico de sus más legítimas costumbres, adaptarse a las formas occidentales de convivencia propició la asunción de modos travestuales, pues, como menciona Barthes (1978) lo que les da más horror es precisamente parecer disfrazado. Por ello, guarda o modifica sus trajes típicos hasta tanto las formas hegemónicas del poder, le indiquen cuáles serán los momentos oportunos para exhibirlos.

Estos instantes, como es conocido, no serán otros que los períodos festivos, carnavales, celebraciones de fechas religiosas significativas; momentos donde la voluntad del poder decide el relajamiento de normativas políticas y religiosas. En este lapso han de manifestarse las distintas identidades en aparente armonía. El poder colonial gozó siempre del divertimento que producían estas fiestas populares, donde la exposición de las distintas identidades étnicas y sus modos de actuar, se les antojaba como actos lúdicos, propios de conciencias que fungían con grácil ingenuidad, expresión ordinaria de sujetos sin emancipar. Esta laxación normativa es una clara expresión de inculturación.

Ahora, la carnavalización actúa psicológicamente sobre el hombre, acentuando el mestizaje sincrético. Cuando el indígena o el negro fueron forzados a portar ciertos atributos del vestuario occidental debió sentirse asimismo "disfrazado”. Paradójicamente, cuando este mismo sujeto absorbió finalmente el herramental sígnico-simbólico del hombre occidental, entonces encontró formas despectivas sugerentes para señalar, entre sus propios atuendos, cierta condición de disfraz. En este sentido podemos agregar que, el mestizaje propició los espacios manifiestos del travestismo cultural.

\section{LEGITIMACIÓN DE LA TRAVESTUALIDAD} AL MARGEN DE LA SEXOLOGÍA

iPrefiero que mienta mi alma y no mi vestido!

iMi alma por un vestido!

(Barthes, 1978, p. 209)

Como se observa, el nacimiento de las naciones americanas estuvo también mediado por un proceso donde la transformación del hombre implicó la transformación de su imagen, lo cual representó un ejercicio de penetración ideológica perenne. Se señala además, cómo entre la vestimenta que se abandona, o en la adoptada, se modela la totalidad de ese "hombre nuevo". Pero este proceso tiene sus espacios físicos precisos, los cuales no serán otros que las zonas urbanas.

Las ciudades americanas en su etapa colonial, construidas bajo normas dispuestas por las metrópolis occidentales poseen características bastante regulares. En primer lugar se establecen como espacios cerrados, lo cual señala el sentido inclusivo y/o excluyente de su topografía. La actividad social estratificada quedará sujeta al tipo de actividad que los hombres realicen, marcándolos no sólo racialmente, sino por el tipo de labor que desempeñan para ganarse la vida.

En este sentido, la arquitectura de la colonia y su desarrollo entre los siglos XVI, XVII y XVIII, mantuvo los presupuestos constructivos medievales donde la ciudad es pensada como un bastión defensivo. El sistema constructivo de cuadras cerradas es de hecho un resultado del 
pensamiento belicista europeo materializado arquitectónicamente. Si se observa la planta de estas ciudades se ve cómo las casas se alinean en cuadro cerrado, dejando hacia su interior patios comunes donde se resguardan animales, provisiones y agua.

El trazado de las calles, en las ciudades cercanas al mar o grandes ríos, se disponía hacia estos enclaves mercantiles. En aquellas ciudades donde su actividad económica giraba alrededor de otras formas de comercio lejanas del mar, el trazado se realizaba haciendo coincidir todas las arterias hacia grandes plazas públicas que en realidad encubrían sus funciones militares como plazas de armas. En estas plazas públicas tenían lugar las actividades comerciales, lo cual las distinguía como espacios destinados a la socialización. Cerca de ellas se construían los edificios mejores, símbolos del poder occidental: grandes catedrales, iglesias, monasterios, consistorios, teatros, recintos militares, etc. Estos espacios públicos exigían comportamientos, vestuarios y ademanes propios de la vida citadina, configurándose como áreas "donde se opera minuciosamente el cambio de identidades" (Barthes, 1978, p. 237). Se está de acuerdo en que, los grupos étnicos amerindios que se mantuvieron al margen del contacto con las ciudades, manifestaron un proceso de penetración cultural menos intenso, lo cual propició en cierta medida la conservación de sus identidades.

El indio se percata tempranamente de que el hombre mestizo, tanto el citadino como el campesino, padece de una "flacidez identitaria" en su conciencia que lo hace partícipe de un "celo travestual", donde la percepción del disfraz es sufrido ambiguamente por ambos.

Cada sujeto vería en el otro el carácter travestido de su condición. El hombre de ciudad veía en el campesino un ser impopular por mantener aquella usanza característica del sujeto sincretizado y que incorporaba elementos del vestuario occidental junto a otros propios de alguna etnia indígena, lo cual, para el hombre citadino, representaba la arbitrariedad carnavalesca. Por otra parte, el campesino observó en el hombre de ciudad un sujeto deslegitimado, indigno por haber abandonado totalmente su relación con la tierra, y las vestes que lo identificaban. Como se sugiere, ambos se percibían travestidos. Por último, el indio ve en el hombre mestizo un sujeto híbrido, poco legítimo, el cual pretende "blanquear" su condición mediante la apariencia que le aportan las vestes occidentales.

\section{LA ANGUSTIA DEL TRAVESTI: UN ACERCAMIENTO AL ESPACIO ANTROPOLÓGICO DE LA SOBREMODERNIDAD}

Barthes (1978), afirma, todo subsiste y sin embargo nada pertenece a nadie, cada cosa presente en su forma completa está vaciada de esa tensión combativa que segrega la propiedad, hay pérdida, no de los bienes, sino de las herencias y de los herederos.

El hombre latinoamericano, que ha visto lacerada sus tradiciones tantas veces, debido al accionar constante de los modelos hegemónicos occidentales, se ve hoy,-más que nunca-, necesitado de un reordenamiento de su identidad. El desgaste producido por largos períodos beligerantes seguido de sucesivos gobiernos dictatoriales, depositaron una profunda apatía hacia el accionar sociopolítico.

En este sentido, intenta recobrar su herramental sígnico-simbólico como parte de una estrategia ante la inminencia de la globalización neoliberal. Las nuevas "ofertas" de políticas económicas,-ahora proveniente de los Estados Unidos-, solo han generado un mayor descentramiento identitario, convirtiendo al hombre latinoamericano en un sujeto cada vez más distanciado de su identidad cultural y mucho más identificado con el "hombre masa" que Ortega y Gasset (1958) había definido como "hombres boyas que van a la deriva (...) se sienten como todo el mundo y a sabor por ser idénticos a los demás". (p.42)

El hombre boya latinoamericano será entonces, un ser comprometido con la posmodernidad, para el cual, su historia es más anhelada como retórica cinematográfica elaborada desde Hollywood, que como nutriente ideológico imprescindible. Su construcción social permanece en el deleite esteticista, realizando paupérrimos esfuerzo por identificarse. Su preocupación se centra en "ser como todo el mundo"; pero este, "todo-mundo", tiene señalada su geografía, los Estados Unidos.

Por tanto, todos los esfuerzos paradójicos del hombre latinoamericano contemporáneo, -que de paso, no vive la posmodernidad-, sino que entra y sale de ella mediante el uso de las redes sociales, irá hacia la laxación de sus compromisos identitarios para alcanzar la imagen-otra, aquella que es generada delicadamente por eficaces formas de hegemonía cultural. Esto ha preparado el terreno para que germine la "desherencia" de la que Barthes (1978) hablaba, la cual crea el ambiente propicio para edificar la angustia del travesti, donde, todo existe y sin embargo nada pertenece a nadie, cada cosa 
presente en su forma completa está vaciada de esa tensión combativa que segrega la propiedad, hay pérdida, no de los bienes, sino de las herencias y de los herederos.

La sobremodernidad, refiere Augé (2008) que es también la homogeneización de las necesidades y de los comportamientos de consumo, nadie puede negar que nuestras sociedades se sumergen cada vez más en este proceso de homogeneización, creador de espejismos de dimensiones globales, se usan los mismos autos, las mismas vestes, se anhela viajar hacia los mismos sitios, se adaptan las economías corrigiendo distancias con las economías del primer mundo, etc. Todo esto connota una intensificación de la travestualización.

Por ello, la problemática identitaria es hoy, una mortificación de consonancia para una Latinoamérica que se enfrasca aún en la estructuración de lo moderno desde cauces propios. No obstante, se ve sometida a soportar la presión de Europa y los Estados Unidos, dos entidades que ya han "licuado la modernidad",-para usar el término del sociólogo Bauman (2004), modernidad líquida, la cual afecta directamente al hombre latinoamericano al no poder resolver, problemas socioeconómicos de los estados, desde políticas internas, las cuales, se ven cada vez más diluidas o licuadas, por políticas globales neoliberales y que inciden directamente sobre las economías.

En realidad las sociedades actuales son asediadas por la construcción de semejanzas de la felicidad posmoderna, la utopía de tales propósitos no alcanza otra cosa que bordear los cuerpos con imágenes que se adhieren cohesivamente a las conciencias en busca de su corporeidad. Asirlas es el fracaso, no hacerlo, los convierte en extraños, alternos, alienados, incluso, disidentes escurridizamente distantes.

Sobre esta cuestión es digno señalar que, los esfuerzos de las políticas culturales actuales de Latinoamérica, se erigen como un discurso de resistencia que pretende mostrar la diferencia como anhelo de corporeidad integracionista; conformándose la ontología de lo diverso y creando además, el enriquecimiento positivo de lo travestual, evitando a toda costa, que nos convirtamos en espacio disoluto del anonimato, según lo expresado por Augé (2008). Se estructura el debate intercultural como solución objetiva que observa la pertinencia del diálogo, como fórmula eficaz para el desarrollo pleno del hombre.

\section{CONCLUSIONES}

Hoy día el proceso híbrido y de mestizaje ha ocupado un espacio importante en Latinoamérica y ha generado cambios favorables en la vida moderna de estos tiempos. El escenario en el que tiene lugar las diversas culturas indígenas unidas a las tradiciones europeas y africanas, han logrado identificarse en un mismo medio. Se ha dado paso a un hombre que busca la estabilidad de la imagen nueva que fue generada por el mestizaje, sin la necesidad de la presencia de los opuestos. En este asunto mantienen vigencia las profecías religiosas para las futuras generaciones, al caracterizar al hombre como un ser que se intuye en la imagen.

El travestismo es un fenómeno cultural que surge, en el roce físico, puede tener varias formas de representarse y para que llegue a mostrarse debe transcurrir un período largo para que ambas culturas interpreten y asuman las formas herramentales sígnicos-simbólicos.

\section{REFERENCIAS BIBLIOGRÁFICAS}

Augé, M. (2008). Los no lugares. Espacios del anonimato. Una antropología de la sobremodernidad. España: Gedisa.

Barthes, R. (1978). Elgrado cero dela escritura. México: SigloXXI.

Bauman, Z. (2004). Modernidad Líquida. México: Fondo de Cultura Económica.

Canclini, N. (1990). "Culturas Híbridas. Estrategias para entrar y salir de la modernidad”. Argentina: Paidós.

Danto, A.C. (2005). El abuso de la belleza; la estética y el concepto de arte. Madrid: Paidós.

Dussel, E. (1994). El Encubrimiento del Otro: Hacia el origen del mito dela modernidad. La paz: U.M.S.A. Facultad de Humanidades y Ciencias Sociales.

Hegel, G.W.F. (1995), Lecciones sobre la Historia de la Filosofía. México: Fondo de Cultura Económica.

Heidegger, M. (1988). Identidad y diferencia. Barcelona: Anthropos.

La Santa Biblia. (1569).Versión de Casidoro de Reina. Recuperado de http://www.librodot.com.

Lezama. J. (2010). La Expresión americana. La Habana: Letras Cubanas.

Marcusse, H. (1978). Eros y Civilización. La Habana: Instituto Cubano del Libro.

Ortega y Gasset, J. (1958). La Rebelión de las Masas. Madrid: Espasa Calpe.

Vasconcelo, J. (1925). La raza cómica. Madrid: Imprenta Helénica. 